\title{
Prevalence and Determinants of Genitourinary Syndrome among Postmenopausal Women of Eastern UP: A Cross Sectional Study
}

\author{
Aradhana Singh $^{1}$, Reena Srivastava ${ }^{2}$, Vani Aditya ${ }^{3}$, Jaya Shukla ${ }^{4}$ \\ ${ }^{1}$ Associate Professor, Dept. of Obstetrics and Gynaecology, BRD Medical College, Gorakhpur, UP, India. \\ ${ }^{2}$ Ex Professor and Head, Dept. of Obstetrics and Gynaecology, BRD Medical College, Gorakhpur, UP, India. \\ ${ }^{3}$ Professor \& Head of Dept. of Obstetrics and Gynaecology, BRD Medical College, Gorakhpur, UP, India. \\ ${ }^{4}$ Resident, Dept. of Obstetrics and Gynaecology, BRD Medical College, Gorakhpur, UP, India.
}

\begin{abstract}
Objective: This study was centered to explore the prevalence and determinants of genitourinary syndrome of menopause (GSM) in postmenopausal women of Eastern, Uttar Pradesh (UP).

Methodology: A cross sectional study was performed, over a period of 6 months (September 2018 to February 2019), on 162 women, who had attained menopause one or more years back, visiting to Gynecology OPD of B.R.D. Medical College, Gorakhpur, Uttar Pradesh and had given consent for participation. Using a pre structured questionnaire, the participating women were questioned about genitourinary complains, and the relationship between these symptoms and other factors were determined.

Results: The prevalence of genitourinary syndrome was found to be $38.6 \%$. The most prevalent genital symptom was vaginal irritation/burning (69.35\%), followed by vaginal dryness $(61.29 \%)$. Increased frequency of micturition (54.83\%) and dysuria (51.6\%) were the most prevalent urological symptoms. However, dyspareunia, in sexually active females, was the most common $(14.52 \%)$ symptom. Most prevalent signs were loss of vaginal rugae (88.71\%) and vaginal pallor $(69.35 \%)$. The prevalence of genitourinary symptoms was higher in women already having urogynecological pathologies, like stress incontinence (OR 3.6), vaginal prolapse (OR 4.43), urinary tract infections (OR 2.77). BMI $>30 \mathrm{~kg} / \mathrm{m}^{2}$ was found to be an important determinant for genitourinary syndrome.

Conclusion: The prevalence of GSM is very high in Eastern UP. There is an urgent need that all Government and non-Government health sectors should have a menopausal clinic, with the aim of timely diagnosis and treatment and to improve the quality of life of menopausal women.
\end{abstract}

Key words: - genitourinary syndrome; menopause; dyspareunia; vaginal dryness.

\section{INTRODUCTION}

Menopause is an accepted, universal phenomenon that occurs in a woman's life. World Health Organization has defined menopause as, permanent cessation of menstruation, for 12 consecutive months, due to loss of ovarian functions ${ }^{1}$. Worldwide, the average age of natural menopause is 51 years, while in India, it is at a rather young age of 46 years $^{2}$. About $70 \%$ of menopausal women experience somatic, psychological, vasomotor, sexual and genitourinary symptoms. Of them, about $50 \%$ experience genitourinary and sexual symptoms ${ }^{3}$ called "Genitourinary Syndrome of Menopause" (GSM). GSM is a new terminology, approved by the "International Society for the Study of Women's Sexual Health" (ISSWSH) and the "North American Menopause Society" (NAMS), in 2014, to replace the earlier used 
term, vulvovaginal atrophy and atrophic vaginitis ${ }^{4}$.

Unlike vasomotor symptoms of menopause, genitourinary symptoms are chronic, progressive and become worse, rather than improve, over time. GSM encompasses signs and symptoms of vulvovaginal, urinary tract and sexual dysfunction, secondary to hypoestrogenism of menopause. Vulvovaginal symptoms have been reported by $45 \%-65 \%$, urinary symptoms by about $20 \%-50 \%$ and sexual symptom by about $20 \%-40 \%$ menopausal women, in different studies ${ }^{5,6,7}$.

Despite such a high prevalence of genitourinary symptoms of menopause, it remains underdiagnosed and undertreated. The probable reasons being, unawareness, associating the symptoms with natural aging and hesitancy to talk about their symptoms with family members and practitioners. There is a lack of knowledge, that the symptoms can be treated and their quality of life be improved.

With increasing life expectancy, women in India, on an average, could spend approximately 30 years, in postmenopausal stage of life. Hence GSM needs urgent attention and demands high priority in our country.

Although, menopause related symptoms have been extensively studied, studies regarding GSM, has not gained much attention in India and especially in Eastern UP. No data regarding GSM, is available from Eastern UP region of India. This study was conducted with an objective to measure prevalence and identify factors, other than menopause, affecting genitourinary symptoms among menopausal women attending a tertiary care facility of Gorakhpur, which caters to a wide population from Gorakhpur, Basti, Santkabirnagar, Maharajganj, Kushinagar, Deoria, Mau and Western Bihar. These patients are representative of Eastern UP.

\section{METHODS}

This single center, cross sectional and observational study, involved postmenopausal women, visiting gynecology OPD of B.R.D. Medical College, Gorakhpur, over a period of 6 months (September 2018 - February 2019). Sampling frame was, all menopausal women visiting Gynecologic OPD of BRD Medical College, Gorakhpur and sampling technique was purposive sampling.

This study included 162 postmenopausal women, visiting gynecologic OPD during the study period, who had attained menopause one or more years back, and gave consent to participate, after explaining to them, the structure and nature of this study.

\subsection{Exclusion criteria -}

1. Perimenopausal women

2. Postmenopausal women with -

- surgical menopause,

- already on hormone or non-hormonal replacement therapy,

- on chemotherapy or radiotherapy for a known malignancy,

- having abnormal cytology in pap smear with/without suspected malignancy,

- women having serious disease or mental retardation.

- having chronic disease or any organ dysfunction or skin disease,

- on antiestrogen, antipsychotic, steroid or antidepressant medication,

- using lubricant powder, irritant panty liners.

2.2 Study tool - All eligible women were given a structured questionnaire which consisted of two parts.

Part 1- Included general information, including socio-clinicodemographic data, obstetrical, menstrual and sexual history, personal and family history.

Part 2- consisted information regarding GSM symptoms, through a checklist of 20 problems (6 vulvovaginal symptoms, 7 urinary symptoms and 7 sexual symptoms) with yes or no options. 

of Eastern UP: a cross sectional study.

\subsection{Data analysis-}

The data were analyzed using the Statistical Package for the Social Sciences (SPSS) program, version 22. Descriptive analyses were conducted to measure mean values and standard deviations for continuous variables and proportions for the categorical variables. For comparisons between groups and single factor analysis, Pearson's Chi Square test was used. Binary logistic regression analysis was used to evaluate the relationship between demographic characteristics and GSM. A pvalue $<0.05$ was set as the significance threshold.

\section{Tables}

Table 1. Demographic characteristics of the participants

\begin{tabular}{|l|l|l|}
\hline Demographic characteristics & $\begin{array}{l}\text { Number } \\
\text { (n= 162) }\end{array}$ & $\begin{array}{l}\text { Proportion } \\
(\%)\end{array}$ \\
\hline Age (years) & & \\
$40-50$ & 45 & 27.8 \\
$50-60$ & 75 & 46.3 \\
$>60$ & 42 & 25.9 \\
\hline Education & & \\
Illiterate & 84 & 51.9 \\
Primary school & 31 & 19.1 \\
Middle school & 16 & 9.9 \\
High school & 22 & 13.5 \\
Intermediate or higher & 9 & 5.6 \\
\hline Socioeconomic status & & \\
Lower & 83 & 51.2 \\
Upper lower & 54 & 33.3 \\
Middle & 25 & 15.4 \\
\hline BMI & & \\
<25 & 24 & 14.8 \\
25-30 & 82 & 50.6 \\
$>30$ & 56 & 34.6 \\
\hline Duration of menopause(years) & & \\
1-5 & 72 & 44.4 \\
$>5$ & 90 & 55.6 \\
\hline Sexual activity: & 19 & $11.7 \%$ \\
Sexually Active & 143 & $88.3 \%$ \\
Sexually Inactive &
\end{tabular}

Table 2. Prevalence of genitourinary symptoms

\begin{tabular}{|l|l|l|}
\hline Genitourinary symptoms & $\begin{array}{l}\text { Number } \\
(\mathbf{n = 6 2})\end{array}$ & $\begin{array}{l}\text { Proportion } \\
(\mathbf{\%})\end{array}$ \\
\hline vulvovaginal symptoms & $\mathbf{5 1}$ & $\mathbf{8 2 . 2 5}$ \\
Irritation/burning & 43 & 69.35 \\
Vaginal dryness & 38 & 61.29 \\
Pelvic pain & 37 & 59.60 \\
Discharge per vaginum & 34 & 54.80 \\
Itching & 13 & 20.96 \\
\hline Urological symptoms & $\mathbf{4 6}$ & $\mathbf{7 4 . 1 9}$ \\
Increased frequency of micturition & 34 & 54.83 \\
Dysuria & 32 & 51.60 \\
Recurrent UTI & 17 & 27.41 \\
Urgency & 11 & 17.74 \\
Stress incontinence & 10 & 16.13 \\
\hline Sexual Symptoms & $\mathbf{1 6}$ & $\mathbf{2 5 . 8 0}$ \\
Dyspareunia & 9 & 14.52 \\
Bleeding after intercourse & 7 & 11.29 \\
Arousal Difficulty & 6 & 9.67 \\
\hline
\end{tabular}

Table 3: - prevalence of genitourinary signs

\begin{tabular}{|l|l|l|}
\hline Signs & $\begin{array}{c}\text { Number } \\
(\mathbf{n = 6 2})\end{array}$ & $\begin{array}{l}\text { Proportion } \\
(\boldsymbol{\%})\end{array}$ \\
\hline Loss of vaginal rugae & 55 & 88.71 \\
\hline Vaginal pallor & 43 & 69.35 \\
\hline Petechiae/fissures/fragility & 39 & 62.90 \\
\hline Decreased elasticity of vagina & 31 & 50 \\
\hline Prominent urethral meatus & 21 & 33.87 \\
\hline Introital retraction & 18 & 29.08 \\
\hline
\end{tabular}


Aradhana Singh et.al. Prevalence and determinants of genitourinary syndrome among postmenopausal women of Eastern UP: a cross sectional study.

Table 4: - sociodemographic determinants of GSM

\begin{tabular}{|c|c|c|c|c|c|}
\hline Sociodemographic determinants & $\begin{array}{l}\text { Total } \\
\mathrm{n}=162\end{array}$ & $\begin{array}{l}\text { GSM } \\
\mathrm{n}=62\end{array}$ & $\begin{array}{l}\text { Non-GSM } \\
\mathrm{n}=100\end{array}$ & Odds Ratio & $\begin{array}{l}P \text { value } \\
(<0.05)\end{array}$ \\
\hline \multicolumn{6}{|l|}{ Education } \\
\hline Illiterate & 84 & 39 & 45 & \multirow[b]{2}{*}{2.07} & \multirow[b]{2}{*}{0.026647} \\
\hline Literate & 78 & 23 & 55 & & \\
\hline \multicolumn{6}{|l|}{ Socioeconomic status } \\
\hline Lower & 83 & 35 & 48 & \multirow[b]{2}{*}{1.40} & \multirow[b]{2}{*}{0.295551} \\
\hline Upper lower and middle & 79 & 27 & 52 & & \\
\hline \multicolumn{6}{|l|}{ Duration since menopause } \\
\hline $1-5$ years & 72 & 21 & 51 & \multirow[b]{2}{*}{2.03} & \multirow[b]{2}{*}{0.032962} \\
\hline$>5$ years & 90 & 41 & 49 & & \\
\hline
\end{tabular}

Table 5: - Association of GSM with urogynecological pathologies:

\begin{tabular}{|c|c|c|c|c|c|}
\hline \multicolumn{2}{|l|}{ Urogynecological Pathologies } & $\begin{array}{l}\text { GSM } \\
(n=62)\end{array}$ & $\begin{array}{l}\text { NON-GSM } \\
(\mathbf{n}=100)\end{array}$ & Odds Ratio & $\begin{array}{l}P \text { value } \\
(<0.05)\end{array}$ \\
\hline \multirow{2}{*}{$\begin{array}{l}\text { Stress Incontinence } \\
\mathrm{n}=15\end{array}$} & YES & 10 & 5 & \multirow[b]{2}{*}{3.6} & \multirow[b]{2}{*}{0.017538} \\
\hline & $\mathrm{NO}$ & 52 & 95 & & \\
\hline \multirow{2}{*}{$\begin{array}{l}\text { Recurrent Urinary Tract Infection } \\
\mathrm{n}=29\end{array}$} & YES & 17 & 12 & \multirow[b]{2}{*}{2.77} & \multirow[b]{2}{*}{0.012837} \\
\hline & NO & 45 & 88 & & \\
\hline \multirow{2}{*}{$\begin{array}{l}\text { Vaginal Prolapse } \\
\mathrm{n}=40\end{array}$} & YES & 26 & 14 & \multirow[b]{2}{*}{4.43} & \multirow[b]{2}{*}{0.000061} \\
\hline & $\mathrm{NO}$ & 36 & 86 & & \\
\hline
\end{tabular}

\begin{tabular}{|c|c|c|c|c|c|}
\hline Body Mass Index & $\begin{array}{l}\text { Total Patients } \\
(\mathrm{n}=162)\end{array}$ & $\begin{array}{l}\text { GSM } \\
(n=62)\end{array}$ & $\begin{array}{l}\text { Non - GSM } \\
(\mathrm{n}=\mathbf{1 0 0})\end{array}$ & Odds Ratio & $P$ value \\
\hline Obese $>30 \mathrm{~kg} / \mathrm{m}^{2}$ & 56 & $39(62.9 \%)$ & $17(17 \%)$ & \multirow[b]{2}{*}{8.27} & \multirow[b]{2}{*}{0.00001} \\
\hline Nonobese $<30 \mathrm{~kg} / \mathrm{m}^{2}$ & 106 & $23(37.1 \%)$ & $83(83 \%)$ & & \\
\hline
\end{tabular}

\section{RESULTS AND DISCUSSION}

Estrogen receptors are present in vagina, vulva, musculature of pelvic floor, endopelvic fascia, urethra and bladder trigone, during reproductive life. Their level decline with menopause, leading to marked atrophic changes and symptoms characteristic of vulvovaginal, urinary tract and sexual dysfunction ${ }^{8}$.

Atrophic changes in vagina are characterized by thinning of epithelium, loss of rugation and reduced secretion during coitus. The atrophic vagina is gradually traumatized, heal by fibrosis and consequently diminishes in size and length. Lubrication of vagina is a process of transduction, in response to congestion of fluid in perivaginal tissue. In menopause, this lubrication diminishes following atrophic change, giving rise to sexual symptoms ${ }^{9}$.

Atrophic change also affects urethra and trigone of bladder, leading to urinary symptoms like dysuria, frequency and urge incontinence. The tone of pelvic muscles and elasticity of the pelvic ligaments is gradually lost, which results in lower closing pressure of urethra and incontinence ${ }^{10}$.
The mean age of the 162 study participants was $59.5 \pm 8.4$ years. GSM was reported by $38.6 \%$ of participants (table 2 ). This prevalence rate is comparable with that of studies by Geng et al ${ }^{11}$, Chua Y. et $\mathrm{al}^{12}$, Nappi R.E. et $\mathrm{al}^{13}$. However, contrary findings were documented from other two studies too. Moral E.et $\mathrm{al}^{14}$ found that GSM is very prevalent in Spanish postmenopausal women, affecting up to $70 \%$ of those consulting a gynecologist. Similarly, in Franklin José Espitia De La Hoz ${ }^{15}$ study involving 558 women from Colombia, the prevalence of genitourinary syndrome of menopause was $51.6 \%$. The decreased prevalence reported in the present study, might be due to stigma in the population studied, to come out with their actual symptoms. Also, the prevalence of GSM would have been varied, had larger group been studied.

The most prevalent vulvovaginal symptom was vaginal irritation / burning, amounting to $69.35 \%$ in the present study (Table 2). Whereas, vaginal dryness was reported as a very common complaint, among postmenopausal women with GSM, in other studies; such as, Geng et $\mathrm{al}^{11}$, Chua Y.et al ${ }^{12}$ and Moral E. et $\mathrm{al}^{14}$. In Italian AGATA study $56.9 \%$ women had vaginal 
irritation and burning, which is similar to this study ${ }^{16}$.

Vaginal dryness was the most commonly experienced symptom and was found in $100 \%$ of menopausal women studied in AGATA study, while it was experienced by $61.29 \%$ women in this study. In REVIVE survey, involving 3046 postmenopausal women, $55 \%$ women had vaginal dryness, which was the most common symptom ${ }^{17}$.

Only $11.7 \%$ women were sexually active in this study. Sexual symptoms were reported by $25.8 \%$ women with GSM, of which, dyspareunia was the most common $(14.52 \%)$ symptom (table 2 ). While in other studies done worldwide, maximum symptoms were pertaining to sexual problem. Prevalence of dyspareunia was reported to be $57 \%$, in a study by Franklin José Espitia De La Hoz ${ }^{15}$. A study conducted by Nappi et $\mathrm{al}^{13}$, on 1805 postmenopausal European women, showed dyspareunia in $34.8 \%$ women. In a Swedish study by Constantin S. Josef and Zoltan Bekkassy $^{18}$, 38\% postmenopausal women were found to have dyspareunia and loss of interest in sexual relations. The less number in the present study, might be due to women taking it for granted, that sexual life is no more after menopause, hence a smaller number of sexually active women and also, hesitancy to talk about problems related to sexual function, to their clinicians.

Prevalence of urological symptoms in this study was $74.19 \%$, of which the most prevalent symptom was increased frequency of micturition $(54.8 \%)$, followed by dysuria (51.6\%) (table 2). However, the prevalence of urinary symptoms was lower in other studies. In AGATA study, done by F Palma et $\mathrm{al}^{19}$, dysuria was reported by $36.1 \%$ patient. Prevalence of frequency of micturition was $22.7 \%$ in a study done by Manonai $\mathrm{J}$ et $\mathrm{al}^{20}$ among Thai women attending Menopause clinic.

Most prevalent sign in this study was loss of vaginal rugae $(88.71 \%$ ) (Table 3 ). This resembles a study done by F. Palma et $\mathrm{al}^{19}$, in which the prevalence of loss of vaginal rugae was found in $92 \%$. Moral et $\mathrm{al}^{14}$ found that most prevalent sign was decreased moisture $(93.7 \%)$.

Studies show large differences between cultures, in sociodemographic and other determinants of $\mathrm{GSM}^{21,22}$. In the present study, GSM was more in patients with low socioeconomic status $(\mathrm{OR}=1.40$, $P=0.295551)$ and significantly associated with lower educational level $(\mathrm{OR}=2.07, P=$ 0.026647) (table 4). In their study, on postmenopausal women, aged 45-55years, Doyel Dasgupta et $\mathrm{al}^{23}$ found a relationship among low educational level and rural residential status.

We also analyzed the prevalence of GSM by subgroups, categorized by time since menopause (Table 4). Urogenital symptoms were significantly more $(\mathrm{OR}=$ 2.03, $P=0.032962)$ in women, who attained menopause more than 5 years back.

GSM was also significantly associated with the presence of urogynecological pathologies in this study; stress incontinence (OR 3.6, $P=0.017538$ ), recurrent UTI (OR 2.77, $P=0.012837$ ), vaginal prolapse (OR 4.43, $P=0.000061$ ) (Table 5). This is consistent with the findings observed by Moral et $\mathrm{al}^{14}$ that GSM was significantly associated with the presence of urogynecological pathologies; Stress incontinence (OR 3.30, $P=0.001$ ) and vaginal prolapse $(P=0.0024)$. On the contrary, association between GSM and urinary tract infection was not significant $(P=0.062)$ in his study.

In this study, GSM was reported significantly more by women who had a BMI $>30 \mathrm{~kg} / \mathrm{m}^{2} \quad(\mathrm{OR}=8.27, \quad P=0.004)$ (Table 6), which is in line with a study done by Geng et $\mathrm{al}^{11}$. They observed that GSM was found to be associated with post menopause $(P=0.001, \mathrm{OR} 1.52)$, at least 2 abortions $(P=0.035$, OR 1.42), BMI $>30$ $\mathrm{kg} / \mathrm{m}^{2}(P=0.032$, OR 1.91) and diabetes $(P=0.041$, OR 1.94).

\section{CONCLUSION}

This study has shown that GSM is common (38.6\%), among postmenopausal 
women of Eastern UP. Most prevalent symptom was vulvovaginal $(82.25 \%)$, followed by urological symptoms $(74.19 \%)$. Sexual symptoms were reported by only $25.80 \%$ women in this study, while studies from developed countries showed that sexual symptoms were most common. In our country, because of stigma, social and cultural constrains and embarrassment, women ignore these symptoms and never seek health assistance.

Obesity was found to be the most important determinant of GSM in this study, apart from lower educational and socioeconomic level.

Health practitioners should proactively raise and discuss genitourinary and sexual symptoms with menopausal women; educate them and treat them. Also, they should enquire into the determinants and other risk factors for GSM. There is an urgent need that all Government and private health sector should have a menopause clinic, to address this hitherto unmet, but significant postmenopausal health concern.

\section{Acknowledgement: None}

\section{Conflict of Interest: None}

\section{Source of Funding: None}

\section{Ethical Approval: Approved}

\section{REFERENCES}

1. Research on the menopause; World Health Organization Technical Report Series 670, WHO, Geneva 1981, ISBN 9241206705.

2. Ahuja M. Age of menopause and determinants of menopause age: A PAN India survey by IMS: J Midlife Health. 2016 Jul-Sep; 7(3): 126-131. doi:10.4103/09767800.191012.

3. Mac Bride MB, Rhodes DJ, Shuster LT. Vulvovaginal atrophy. Mayo Clin Proc 2010; 85:87-94.

4. Portman DJ, Gass ML. Vulvovaginal Atrophy Terminology Consensus Conference Panel. Genitourinary syndrome of menopause: new terminology for vulvovaginal atrophy from the international society for the study of women's sexual health and the North American menopause society. Climacteric 2014; 17:557-63.

5. Erekson EA, Li FY, Martin DK, et al. Vulvovaginal symptoms prevalence in postmenopausal women and relationship to other menopausal symptoms and pelvic floor disorders. Menopause 2016; 23:36875

6. Aydin Y, Hassa H, Oge T, et al. Frequency and determinants of urogenital symptoms in postmenopausal Islamic women. Menopause 2014; 21:182-7

7. Sarrel PM. Sexuality and menopause. Obstet Gynecol. (1990) 75:26S-35S. doi: 10.1097/00006250-199004001-00006.

8. Nappi RE, Palacios S. Impact of vulvovaginal atrophy on sexual health and quality of life at post menopause. Climacteric 2014; 17:3-9.

9. Levin KB, Williams RE, Hartmann KE. Vulvovaginal atrophy is strongly associated with female sexual dysfunction among sexually active postmenopausal women. Menopause 2008; 15: 661-6.

10. Robinson D, Cardozo LD. The role of estrogen in female lower urinary tract dysfunction. Urology 2003; 62: 45-51.

11. Tao, Minfang \& Geng, L. \& Zheng, Y. \& Zhou, Y. \& Li, C. (2018). The prevalence and determinants of genitourinary syndrome of menopause in Chinese mid-life women: a single-center study. Climacteric.21. 1-5. 10.1080/13697137.2018.1458832.

12. Chua Y, Limpaphayom KK, Cheng B, Ho CM, Sumapradja K, Altomare C, Huang K. Climacteric. 2017 Aug; 20(4):367-373. Epub 2017 Apr 28.

13. Nappi RE, Panay N, Rabe T, Krychman M, Particco M. Results of the European REVIVE (REal Women's VIew of Treatment Options for Menopausal Vulvar/Vaginal ChangEs) survey. 10th Congress of the European Menopause and Andropause Society; May 20-22, 2015; Madrid, Spain.

14. Moral E, Delgado JL, Carmona F, Caballero B, Guillán C, González PM, SuárezAlmarza J, Velasco-Ortega S, Nieto C, as the writing group of the GENISSE study. Climacteric. 2018 Apr; 21(2):167-173. Epub 2018 Feb 7.

15. Espitia De $\mathrm{La} \mathrm{Hoz}$ Franklin José. Prevalence of genitourinary syndrome of menopause and impact on sexuality of women in Quindío (Colombia), 2013-2016. 
Rev Colomb Obstet Ginecol [Internet]. 2018 Dec [cited 2019 Nov 23]; 69(4): 249-259.

16. Cagnacci A, Carbone MM, Palma F, et al. Prevalence and association between objective signs and subjective symptoms of vaginal atrophy: the AGATA study. Menopause 2016; 23:1139-45.

17. Palacios S, Cancelo MJ, Castelo Branco C, et al. Vulvar and vaginal atrophy as viewed by the Spanish REVIVE participants: symptoms, management and treatment perceptions. Climacteric 2017;20: 55-61.

18. Iosif CS, Bekassy Z. Prevalence of Genitourinary symptoms in the late menopause. Acta Obstet Gynecol Scand 1984; 63:25760.

19. Palma F, Volpe A, Villa $P$ et al. Vaginal atrophy in women in post menopause. Results from a multicentric observational study: The AGATA study. Maturitas 2016; 83:4.

20. Manonai J, Chittacharoen A, Sarit-Apirak S, et al. Lower urinary tract symptoms in Thai women attending the menopause clinic: prevalence and associated factors. J Med Assoc Thailand 2004;87: 1265-9.

21. Alan S, Gozuyesil E, Gokyildiz S. Effect of menopause on the life of women who experience hot flashes and their healthseeking behaviors. Int J Caring sci. 2016; 9:542-550.

22. Shorey S, Ng ED. The experiences and needs of Asian women experiencing menopausal symptoms: A meta-synthesis. Menopause.2019 May;26(5):557-569. doi: 10.1097/GME.1269.

23. Dasgupta D, Karar P, Ganguly $\mathrm{N}$ et al. Menopause symptoms and its correlates: A study on Tribe and caste population of East India. Curr Gerontol Geriatr Res. 2015; 2015: 984767. doi:10.1155/2015/984767.

How to cite this article: Singh A, Srivastava R, Aditya V et.al. Prevalence and determinants of genitourinary syndrome among postmenopausal women of Eastern UP: a cross sectional study. Int J Health Sci Res. 2021; 11(5):1-7. DOI: https://doi.org/10.52403/ijhsr.20210501 